

\title{
Social Work in Mental Health Contexts and Theories for Practice
}

\author{
Edited by \\ Abraham P. Francis
}


Copyright (C) Abrabam P. Francis, 2014

All rights reserved. No part of this book may be reproduced or utilised in any form or by any means, electronic or mechanical, including photocopying, recording or by any information storage or retrieval system, without permission in writing from the publisher.

First published in 2014 by

\title{
SAGE Publications India Pvt Ltd
}

B1/I-1 Mohan Cooperative Industrial Area Mathura Road, New Delhi 110 044, India www.sagepub.in

SAGE Publications Inc

2455 Teller Road

Thousand Oaks, California 91320, USA

SAGE Publications Ltd

1 Oliver's Yard, 55 City Road

London EC1Y 1SP, United Kingdom

\author{
SAGE Publications Asia-Pacific Pte Ltd \\ 3 Church Street \\ \#10-04 Samsung Hub \\ Singapore 049483
}

Published by Vivek Mehra for SAGE Publications India Pvt Ltd, Phototypeset in 10/12 Adobe Garamond Pro by RECTO Graphics, Delhi and printed at Sai PrintO-Pack Pvt Ltd, New Delhi.

\section{Library of Congress Cataloging-in-Publication Data}

Social work in mental health : contexts and theories for practice / edited by Abraham P. Francis.

pages $\mathrm{cm}$

Includes bibliographical references and index.

1. Psychiatric social work. I. Francis, Abraham P.

HV689.S679 362.2'0425-dc23 $2014 \quad 2014010581$

ISBN: 978-81-321-1739-1 (PB)

The SAGE Team: Supriya Das, Archa Bhatnagar, Rajib Chatterjee and Dally Verghese 
To

my fellow authors

and

my family 
Thank you for choosing a SAGE product! If you have any comment, observation or feedback, I would like to personally hear from you. Please write to me at contactceo@sagepub.in

-Vivek Mehra, Managing Director and CEO, SAGE Publications India Pvt Ltd, New Delhi

\section{Bulk Sales}

SAGE India offers special discounts for purchase of books in bulk. We also make available special imprints and excerpts from our books on demand.

For orders and enquiries, write to us at

Marketing Department

SAGE Publications India Pvt Ltd

B1/I-1, Mohan Cooperative Industrial Area

Mathura Road, Post Bag 7

New Delhi 110044, India

E-mail us at marketing@sagepub.in

Get to know more about SAGE, be invited to $S A G E$ events, get on our mailing list. Write today to marketing@sagepub.in

This book is also available as an e-book.

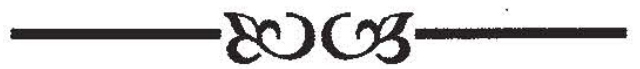




\section{Contents}

List of Illustrations

ix

Foreword by Vimla V. Nadkarni

Acknowledgements xiii

Prologue: The Making of the Book xv

Introduction by Abraham P. Francis and Beth Tinning xxi

Part 1: Context of Social Work Practice

Context of Social Work Practice: An Introduction 3

Robert Bland

1. Global Perspective on Mental Health 7 Venkat Pulla

2. Mental Health Initiatives in India (1947-2010) 28

R. Srinivasa Murthy

3. Mental Health and Social Work Practice in India:

A Historical Perspective 62

Kamlesh Kumar Sabu

4. Emerging Contexts and Contemporary Social Work Practices in Mental Health

Rajeev S. P.

Part 2: Theories That Inform Practice

Theories that Inform Social Work Practice: An Introduction Beth Tinning

5. Recovery Theory and Practice

Robert Bland and Ann Tullgren

6. A Strengths Approach to Mental Health

Venkat Pulla and Abraham P. Francis 
viii Social Work in Mental Health

7. South Asians and Mental Health Issues

Lena Robinson

8. Positive Psychology and Refugee Mental Health: Implications for Social Work Practice

Wendy $L i$ and Abraham P. Francis

9. Crime and Mental Health: Implications for Social

Work Practice

Mark David Chong and Jamie D. Fellows

10. The Nature of Male Coping as a Key Insight for Mental

Health Practice

John Ashfield

11. Gender Inequalities and Mental Health: Towards Resilience and Empowerment

Hurriyet Babacan

12. Disaster Management: A Mental Health Perspective

Brian D. A. Fernandes and Sebastin K. V.

13. Integrative Medicine and Mental Health: Implications for Social Work Practice

Narayan Gopalkrishnan

Appendix 1: Glossary

Appendix 2: Reflective/Practice Questions

About the Editor and Contributors

Index 


\section{List of Illustrations}

\section{Tables}

2.1 Prevalence of Psychosis and Treatment Status in Six States

2.2 Prevalence of Depression and Treatment Status in Six States

4.1 General Health Care System in Kerala

6.1 Questions Suitable for Client Situations

13.1 Utilisation of Complementary and Alternative Medicine Systems

\section{Figures}

1.1 Mental Health Governance 11

1.2 Mental Health Facilities 14

1.3 Professional Manpower 15

1.4 Worldwide Expenditure on Drugs (in USD) 16

6.1 Seven Key Principles of Strengths Practice $\quad 130$

10.1 Reconnecting with and Working Through Experience of a Significant Negative Event

10.2 Sex-specific Bio-behavioural Responses to Stress 217

12.1 General Effects of a Disaster 253 
$x$ Social Work in Mental Health

\section{Boxes}

1.1 Disability Related to Health Conditions 8

1.2 Project Atlas $2001 \quad 10$

1.3 Messages from Mental Health Atlas 2011

1.4 Services Delivered 14

2.1 Challenges for Mental Health Care in India 31

2.2 National-level Initiatives to Address Mental Health Needs 37

2.3 Objectives of the National Mental Health Programme 40

2.4 Approaches to the National Mental Health Programme 40

2.5 Five Strategies of the National Mental Health Programme
in the 10th Five-Year Plan

2.6 Objectives of the District Mental Health Programme 44

6.1 The Objectives for Social Work Intervention in Mental Health 127

6.2 Conversation between Social Worker and Client 132 


\section{Foreword}

I am pleased to introduce this book titled Social Work in Mental Health: Contexts and Theories for Practice, edited by Abraham P. Francis, Senior Lecturer at the James Cook University in Australia. It has been quite a challenge for him to bring together a range of professionals, mostly social work educators and practitioners from Australia and India on social work practice in mental health. This book will be useful in teaching, skill development of social work practitioners and for future researches and collaborations. The chapters cover current practices, theoretical debates, social work interventions and challenges faced by the social workers in the field of mental health.

Mental, neurological and substance use disorders are common in all regions of the world, affecting every community and age group across all income countries. While 14 per cent of the global burden of disease is attributed to these disorders, most of the people affected- -75 per cent in many low-income countries-do not have access to the treatment they need (WHO 2013). Only between 76 per cent and 85 per cent of people with severe mental disorders in low- and middle-income countries receive no treatment for their mental health conditions compared to the corresponding figures for high-income countries, which were also unenviable, that is between 35 per cent and 50 per cent (WHO 2011 and 2013).

There is a growing recognition of the global community that countries, especially low- and middle-income countries need to pay greater attention to mental disorders and prevention of mental health problems as a large number of those can be prevented and treated. As people living with mental disorders have to suffer the dual burden of the disease and the stigma arising out of gross misconceptions, there is great need to develop appropriate interventions to change attitudes and to protect the human rights of this highly vulnerable population. Among those caretakers and health care providers, professional social workers play a major role in working with the affected individuals, their families and the community at large. Professional social work also has a very significant contribution to make in the prevention of these disorders and for the promotion of mental health. 
I am sure that this book will find a place in many of our social work educational institutions, especially in the Asia and Pacific region, and will be a good reference book for our social.work students and faculty.

Vimla V. Nadkarni, PhD

President, International Association of Schools of Social Work (IASSW) Vice-President, Bombay Association of Trained Social Workers (BATSW) Founder Dean and Professor (Retd), School of Social Work Tata Institute of Social Sciences Mumbai, India

\section{References}

World Health Organization. 2011. Global Burden of Mental Disorders and the Need for a Comprehensive, Coordinated Response from Health and Social Sectors at the Country Level. Report by the Secretariat. Retrieved on 14th April 2014 from http://apps.who.int/gb/ebwha/pdf_files/EB130/B130_9-en.pdf

- 2013. WHO Mental Health Gap Action Programme (mhGAP). Retrieved 14th April 2014 from http://www.who.int/mental_health/mhgap/en 


\section{Acknowledgements}

It is with a great sense of hope, excitement and accomplishment that I would like to present this book to the readers, especially social work students. There have been a number of people who have been instrumental in bringing this book project to fruition. I would like to first of all acknowledge the loving providence of God, who protected me and blessed me with some fantastic colleagues and friends to work on this project. Likewise, support and assistance have come from many corners for which I am indebted and grateful.

Mental Health as a subject has always been a fascination for me. During the course of my own studies and practice I developed a passion for this subject. The greatest of all learning in this field occurred when I started working with my clients. They taught me a lot-many of which were matters that I had not learned through my formal studies. Therefore, I would like to thank all my clients and colleagues who supported me, guided me and challenged me in my clinical practice. In particular, I would like to thank all my team members at Clare Mental Health, South Australia, and very specially John Banister, our then team leader who allowed and supported me to venture into community mental health practice, and Pat Glenister for mentoring me in mental health social work. Their support has been a key inspiring aspect of my journey in editing this book.

I would like to thank Vimla V. Nadkarni, Professor and Founder Dean, School of Social Work, Tata Institute of Social Sciences, and the President of the International Association of Schools of Social Work for writing a foreword for this book. I would like to also express my gratitude to all chapter authors for offering the readers excellent insight into social work practice within a mental health setting. I am aware that many of them were extremely busy with their teaching, research and other academic commitments, but nevertheless took out time to be a part of this wonderful project. You honour me with your participation in this project, and for that I am truly grateful.

This book would not have been possible without the help and assistance of my students and colleagues at James Cook University. Very special thanks to $S$. Sharma who provided with some anecdotal evidence for this project and for being part of this work. At each step of this journey, my colleagues provided me with overwhelming support and encouragement, particularly 
Mark David Chong, Debra Miles, Wendi Li, Peter Jones, Nonie Harris and Ines Zuchowski.

I am equally indebted to Professor Robert Bland, from the University of Queensland, who constantly encouraged me, provided feedback and mentored me in this project. I am likewise thankful to John Ashfield, from the Australian Institute for Male Health Studies, for his tireless support and inspiration. I also thank Professor Sanjai Bhatt from Delhi University for his support to this project.

During the course of this project, I have been blessed to have come into contact with so many scholars hailing from different walks of life. Some have been able to contribute to this book, while others offered me words of appreciation, direction and further references. I thank them all. I would like to especially thank Professor R. Srinivasa Murthy, who graciously allowed me to reproduce his outstanding paper as a chapter in this book.

I am also deeply touched and honoured by the support of my friends. To that end, I would like to thank my friend Kalpana Goel from the University of South Australia, for her support and excellent suggestions. Special thanks are also due to my friend and colleague Professor Ilango Ponnuswami from Mangalore University for his encouraging words, reviewing some of the chapters and for his insightful comments. My gratitude likewise goes out to my colleague Venkat Pulla, University of the Sunshine Coast, for sharing his knowledge and understanding of strengths-based social work practice and mental health issues with me. He has been a keen supporter of this project and I really thank him for all he has been to me through the various roles that he has played over this period as an author, colleague, supporter and critic. I thank Shoba Ramachandran for critically reviewing some of the chapters that came to us for this book, and doing such a good job at it.

On the production side, I wish to thank Rekha Natarajan, Sutapa Ghosh, Supriya Das, Saima Ghaffar and Anupam Choudhury for their professional support, comments, suggestions and commitment to seeing this work published.

As you can imagine, this has been a long but passionate journey for me and for my family. I thank my wife, Mini, for her critical questions, deep and meaningful reflections and her invaluable suggestions for the book. I also thank my children, Abhijith and Alka, for their understanding, and for patiently waiting for me to help them with their academic work and sports activities. 


\section{Prologue: The Making of the Book}

The inspiration to lead a book on social work practice in mental health did not just happen overnight. There were a couple of incidents and events that influenced my thinking and practice in the field which motivated me to take this work. Social work practice in mental health is an important area of practice. This collection deals with a variety of gaps in the literature and also provides a fresh outlook for an international audience. This book finds a niche for itself as it brings academia that are involved in interdisciplinary practice. A series of incidents has prompted me to shape this book. As a faculty member in social work some 15 years ago, I was responsible for a field placement for one of my students in a mental health hospital in India. At that time, it was not a course unit taught at the college, but a mere placement option in a psychiatric hospital setting that was made available to interested students, although subject to discussion and negotiation with the said medical facility. A number of my peers were a bit concerned about sending students to a place that represented great misery and disappointment for social workers at that time. The question then arose as to whether it would be a prudent action to place a young and naive social work student in a mental health setting that offered a difficult practice context and a grim future. I still remember that a student came bravely to express her keenness. While some of my colleagues were apprehensive about sending her into such a potentially harsh environment, the student not only received a start but finished her placement and went on to do a masters in social work. While I deeply appreciated the practical issues that many of my colleagues in the 1990 s warned me about, clearly there was an ideological difference that permeated our discussions in those years. The primary issue was: Is this place suitable for an undergraduate placement? Or was there an undercurrent of resistance due to stigma attached to mental illness even in the social work field 15 years ago? I did not have a clear answer then; but this made me reflect about the role of social workers in the field of social work practice and was a key motivating factor behind the making of this book.

Meanwhile, I was very keen to provide a safe, supportive environment for my student and an opportunity to see, grasp and fathom for herself and to experience what a gigantic task it would be to be involved with mental health 
issues. The student was well supported and received much appreciation from many, which not only motivated her but also later motivated other students to undertake placement in a psychiatric setting.

I felt that mental health is everybody's business and social workers have a special role to play in this field. Thus began an impulse to write a $\hat{b}$ ook for new students about the role of social work in rehabilitation and/or treatment. For a long time, nearly 15 years, this remained a dream. In the meantime, another student of mine took up the cudgel and wanted to do his placement in a mental health facility, and upon successfully completing it, both these students gave me the confidence, courage and anecdotal evidence to engage in developing culturally appropriate literature and trainings for students in mental health. On reflection, these early challenges really spurred me on to develop meaningful materials that would attempt to de-stigmatise and demystify issues in mental health for my students.

After a long hiatus, I came into contact with my first mental health placement student again in 2011. She was by then actively engaged in social work and was settled in the United States. While we were catching up, she said something to me which rekindled this idea to lead this book. This is what she had to say:

Being a Social Work student in India was always a choice everyone questioned. It was hard for even my own family to sometimes understand what good a degree in social work could be as a career? After all these years of its presence, social work still struggles for its place in the working world as a profession. Starting a career in social work was a decision that I made not just because it was different but also because it offered learning through working. So far, pursuing a career in this field has meant a great experience for me. It has moulded me into the person that I am today and how I perceive the world around me.

During the course of my study (Bachelor's in Social Work), there were several challenges I was faced with, but the major one arose in the final year. I was to be placed for my concurrent fieldwork at a mental health hospital. There were doubts raised by the hospital social workers that Bachelor's students lacked the experience required to make the best of the training in a mental health set-up and to make any contribution as a part of their team. Similar doubts were raised by some of my college faculty members as well, stating that Psychiatric Social Work was much too complicated for Bachelor's students, and had not been attempted before. There also was an unfounded fear within me, making me doubt my own ability to work in that place, since it was so overwhelming to see as much sadness and people dealing with all the problems they had that it almost depressed me. I felt at a personal level that I might not be able to deal with it. 
So the first hurdle in my way I had to leap over was my own mindset, and I did overcome my fear. After my first couple of visits to the hospital, I had an epiphany and realised this is what I wanted to do. I saw that all the people coming in to the clinics everyday were dealing with so much and still doing what they must despite their problems. The people I observed and I was going to work with, themselves, became my inspiration to work there. I believed that this is what I was meant to do, no matter how hard it may seem.

Fortunately for me, our college supervisor had faith enough in my willingness to work there and my readiness to take on what everyone else thought was an oddball of a task. He discussed these issues with the college as well as the hospital's social work department and thus my training started. It was decided that for the first quarter I would only be making observations in the OPD clinics and if the hospital supervisor felt I had learnt enough by then, I could be an active participant in the team's work.

And so it happened, the training began, I made the most of my hours of observation in various outpatient clinics, reading at the library and discussions with the doctors and gaining from the perspective of teams of all professionals and understood the role of social workers in the whole scenario. Upon completion of the first quarter I was gauged by the supervisors and was then allowed to practise at the hospital. With guidance from my supervisors and the hospital doctors I gained knowledge about various psychiatric, psychological and other mental health disorders. But most of all I learnt of the social issues surrounding mental health problems. I came to realise that till date in our country (India), mental health problems were considered a 'taboo'. The families most of the times failed to recognise the actual problems of the patients. Even when they do find out about the problem, they do not wish to seek help for it, for the fear of being ostracised by the society. There were several patients in the rehab centre who had been brought over by their families for treatment, but never taken back by that family member, thinking of them as a liability. This display of sheer apathy on the part of family members was the most difficult to comprehend and saddening. But the reason for such behaviour was clearly the fact that our society still does not understand mental health; even something as depression is looked down upon and people refuse to see doctors for it, fearing what others might think of them. So one can safely say that the role of a social worker in the field of mental health is quite crucial especially in a country like India, where awareness needs to be brought about amongst the masses about these issues and people need to be rid of their biases and prejudices against those ailing.

At the end of the year, my determination and my teachers' belief in me paid off, and I completed the training successfully. Thanks to this experience and all that I learnt from it, I want to be a social worker in the field of mental health. (Personal communication with S. Sharma, 2012) 
My professional experience of working in the mental health sector has definitely influenced my thinking and I was very keen on including the consumer's voice in the subjects that I was responsible for teaching. All of these experiences, reflections and ambitions have in a way, directly or indirectly, affected my ethos and created a thirst in me for wanting to contribute to the social work fraternity. Unfortunately, it has taken almost 15 years for me to crystallise this dream into reality.

The need for such a book was also another factor which spurred me on. This book, therefore, represents an effort to bring together various academics in this field from Australia and India to share their knowledge. There are a number of social workers born in India and employed as mental health social workers in Australia, and there are many others who aspire to provide their therapeutic expertise in this country as well. I hope that this text will intellectually scaffold these groups by facilitating greater awareness of the areas of convergence as well as the points of departure between social work theory and practice in Australia and India.

One in four people develop some kind of mental illness at some point in their lives. But although mental illness is one of the most common health conditions worldwide, it can be one of the hardest to come to terms with. Both for those who are ill, and for those who are close to them. People suffer twice overfrom the illness itself, and because they are shunned by their families, exiled from their communities and isolated by society. (Mental Health Atlas 2011)

From this account, it is apparent that mental health problems are very common in contemporary society. The key message from the Mental Health Atlas 2011 is that the gap between what is needed for mental health care and what is available, remains very large. This gap is also replicated in social work education, especially in developing countries. It is likewise hoped that this book will be useful in teaching, enhancing practitioners' skills and facilitating future research and collaborative endeavours among social workers in these nations. As explained by Professor Robert Bland, 'All social workers, whether in specialist or generalist settings, need specific knowledge, skills and values to work effectively with people with mental health problems' (Bland et al. 2009). The book is therefore aimed at: (a) students pursuing Bachelor of Social Work, Master of Social Work and MPhil in Medical and Psychiatric Social Work; (b) social work practitioners; $(c)$ field educators; $(d)$ researchers; and (e) social work educators. This book will orient the reader through the various local and international concepts used in mental health, the intellectual base for such practice, current practices, models, debates in 
the field, and challenges for social work practice. The contributors to this book have come from various backgrounds and they are from social work, psychology, psychiatry, law, criminology and education, which presents a multidisciplinary view of the current practice models. The book is also enriched by the voice of the consumers, which is also a new direction of practice. Principles of 'social justice and human rights' are the core values. that underpin the philosophical framework of this book as social workers are called to advocate on behalf of the marginalised, under-represented and vulnerable sections of society.

The book is divided into two parts, with each part containing a number of related chapters. The first part sets out the context of social work practice. The second part discusses the various theoretical frameworks that influence the work we do as social workers. At the end of the book, you will find two appendices. Appendix 1 explains the key terms that are used in this book and Appendix 2 provides you with a set of reflective questions that will help the reader to engage in critical reflections and help you formulate an action plan for practice.

I present this book to you in the hope that it will be useful for your critical thinking, education and practice.

Abraham P. Francis

\section{References}

Bland, R., N. Renouf and A. Tullgren. 2009. Social Work Practice in Mental Health. Crows Nest, NSW: Allen and Unwin.

WHO. Mental Health Atlas. 2011. 'Transcript of the Podcast', retrieved from http://www.who.int/mediacentre/multimedia/podcasts/2011/mental_ health_17102011/en/ (accessed: 20 January 2012). 